\title{
Chromosome 2q37 Deletion Syndrome
}

National Cancer Institute

\section{Source}

National Cancer Institute. Chromosome 2937 Deletion Syndrome. NCI Thesaurus. Code C129021.

A syndrome of high phenotypic variability caused by contiguous gene deletions in 2q37.

The inheritance is autosomal dominant. The condition may be characterized by brachydactly type E; mental retardation; short stature; and other skeletal, cardiovascular, and neurologic manifestations. 